\title{
Narrativas de vida sobre a escolarização dos idosos: contribuições na formação inicial dos professores
}

\author{
Bethania Medeiros Geremias ${ }^{1}$ \\ Thayná Luana Borges ${ }^{2}$
}

\section{Resumo}

Neste relato de experiência, analisamos duas narrativas de vida de idosos, produzidas por estudantes de Pedagogia, da Universidade Federal de Viçosa, em 2017, na disciplina Educação na Terceira Idade. Para tanto, nos referenciamos em Daniel Bertaux, que utiliza o recurso da entrevista como estratégia de construção de histórias de vida. Nosso objetivo foi compreender os caminhos trilhados pelos sujeitos entrevistados no processo de escolarização e as contingências que os impediram de frequentar a escola no decorrer da vida. Dentre os obstáculos identificados, destacamos aqueles relativos aos estereótipos de gênero, que se materializam nas escolhas profissionais, reforçando a desigualdade no campo do trabalho e nas instâncias formativas.

Palavras-chave: Formação de Professores; Educação na Terceira Idade; Bertaux; Narrativas de Vida; Trajetória Escolar.

\section{Les récits de vie des personnes âgées dans la formation initiale des enseignants}

\section{Résumé}

Dans ce rapport d'expérience, nous avons analysé deux récits de vie des personnes âgées, produits par des étudiants en pédagogie, de l'Universidade Federal de Viçosa, en 2017, dans la discipline Education des Personnes Âgées. Nous nous référons à Daniel Bertaux, qui utilise la ressource d'interview comme stratégie pour construire des histoires de vie. Notre objectif a été de comprendre les chemins empruntés par les sujets âgées dans les processus scolaire et les aléas qui les ont empêchés d'aller à l'école tout au long de leur vie. Parmi les contingences, nous mettons en évidence celles liées aux stéréotypes de genre, qui se matérialisent dans les choix professionnels, renforçant les inégalités dans le domaine du travail et dans les instances formatrices.

Mots-Clés: Formation des Enseignants; Éducacion des Personnes Âgées; Bertaux; Récits de Vie; Trajectoire Scolaire.

\section{Introdução}

Neste trabalho, buscamos relatar e analisar uma experiência em ensino realizada em 2017, na disciplina Educação na Terceira Idade (ETI), do curso de Pedagogia, da Universidade Federal de Viçosa, localizada em Minas Gerais.

Para que as estudantes tivessem um contato mais aproximado com a temática e com os sujeitos da terceira idade, optamos pela metodologia das narrativas de vida em perspectiva

\footnotetext{
${ }^{1}$ Universidade Federal de Viçosa, Viçosa. bmgeremias@ufv.br

2 Universidade Federal de Viçosa, Viçosa. thayna.borges@ufv.br
} 
etnossociológica, de Daniel Bertaux (2010). Essa é uma estratégia de construção de histórias de vida, baseada no recurso da entrevista, juntamente com a etnografia e a observação direta.

Tal perspectiva permitiu o embasamento para a construção do trabalho realizado pelos estudantes da disciplina citada que, em grupos, entrevistaram idosos com o intuito de compreender os caminhos trilhados por eles no âmbito do processo de escolarização, bem como os obstáculos e as contingências que os impediram de frequentar a escola no decorrer da vida.

Considerando que "não há experiência humana que não possa ser expressa na forma de uma narrativa" (JOVCHELOVITCH; BAUER, 2002, p.91), escolhemos essa abordagem como técnica de ensino e pesquisa na formação de professores visando desenvolver propostas didáticas que formassem os estudantes do curso de Pedagogia para atuarem com o público da terceira idade ou para o trabalho com temáticas envolvendo envelhecimento e educação.

Para abordarmos a temática da escolarização de idosos, é imprescindível dialogarmos com Paulo Freire, pois seus trabalhos, no âmbito da Educação de Jovens e Adultos, contribuem para pensar em uma educação ampla, crítica e direcionada às especificidades desses sujeitos. Conforme esse autor, a educação necessita "estar precedida de uma reflexão sobre o homem e de uma análise do meio de vida concreto do homem concreto a quem queremos educar (ou melhor dito: a quem queremos ajudar a educar-se)" (FREIRE, 1980, p.33-34).

Ao tomarmos em consideração a concreticidade da vida dos idosos entrevistados e as contingências por eles vividas, compreendemos ser necessário um processo de desconstrução de estereótipos sobre a velhice, os quais são construídos e reproduzidos socialmente, marginalizando e excluindo aqueles que, numa visão mercadológica, são considerados inúteis ou desprovidos de capacidades manuais e/ou intelectuais (BOSI, 1994).

Assim, com vistas a contribuir com essa temática na formação de pedagogos/as, utilizamos, durante as aulas da disciplina ETI, a narrativa de vida tanto como metodologia de ensino, quanto de aproximação com os problemas enfrentados pela terceira idade nos seus processos educativos formais ou não formais. A metodologia citada foi definida pela professora da disciplina, durante a construção do plano de curso.

Ao promover um encontro intergeracional entre estudantes (em sua maioria jovem) e idosos do seu entorno nesta disciplina ETI, possibilitamos que as vozes desses sujeitos se 
materializassem nas narrativas. A experiência realizada demonstrou ser possível criar espaços de escuta entre as gerações e, consequentemente, novas relações com a velhice e outras compreensões sobre os sujeitos idosos.

No Estatuto do Idoso/Lei 10741/03 (BRASIL, 2003), é considerada pessoa idosa aquela com idade igual ou superior a 60 (sessenta) anos. Em seu artigo 3ํe encontra-se a escolarização na velhice como um dos direitos desses sujeitos e como dever da família, da comunidade, da sociedade e do Poder Público.

Mediante essa garantia legal, buscamos referenciais que pudessem promover uma aproximação entre estudantes e idosos, bem como a ruptura de estereótipos. O objetivo geral da disciplina foi compreender as especificidades das políticas e legislações direcionadas aos sujeitos da terceira idade, bem como o papel da educação na formação desses e na ressignificação de suas memórias e histórias de vida.

Nesse sentido, em termos de análise posterior das entrevistas, transformadas em narrativas pelas estudantes da disciplina ETI, buscamos: i) analisar como se deu esse processo e os motivos pelos quais uns prosseguiram nos estudos e outros não; ii) entender o anseio desses sujeitos quanto ao retorno aos espaços escolares, e aos obstáculos e/ou facilidades vivenciados.

\section{Envelhecimento e educação de idosos: desafios para a formação de professores}

O envelhecimento é um processo natural que traz inúmeras modificações para o ser humano: físicas, psicológicas e sociais (ZIMERMAN, 2000). Na literatura, as pessoas com mais de sessenta anos são consideradas como pertencentes à Terceira Idade. Tal expressão faz alusão ao tratamento às pessoas mais velhas e se originou na França, por volta de 1970. De acordo com Stucchi (1994), foi nesse país que foram formados os primeiros gerontólogos do Brasil.

No campo da Gerontologia, o envelhecimento não significa uma decadência, mas uma sequência da vida, com suas peculiaridades e características (ALMEIDA; LOURENÇO, 2007). Há diversos elementos que indicam bem estar nessa fase: 
[...] longevidade; saúde biológica; saúde mental; satisfação; controle cognitivo competência social; produtividade; atividade; eficácia cognitiva; status social; renda; continuidade de papéis familiares e ocupacionais, e continuidade de relações informais em grupos primários (principalmente rede de amigos) (NERI, 1993, p.10).

Dentre esses elementos, consideramos a educação formal e/ou não formal como possibilidade de ampliar vivências, conhecimentos e relações interpessoais. Principalmente, quando pesquisas demonstram que muitos idosos buscam nos estudos uma forma de resgatar sonhos antigos, que foram alterados pelas contingências da vida. Conforme Búfalo (2013), as instituições educativas podem se configurar como um novo espaço de educação dos sujeitos idosos. Porém, a autora considera necessários estudos mais atualizados sobre velhice e envelhecimento, permitindo a consolidação dos seus direitos sociais.

Além disso, é preciso levar em conta que o número de idosos no país tende a crescer de maneira vertiginosa. Conforme Neri e Yassuda (2004), há um significativo aumento dessa população em virtude do declínio da taxa de mortalidade, das conquistas médicas e nutricionais, de melhorias nos níveis socioeconômicos, assim como da melhoria da qualidade de vida, entre outros fatores que acarretam aumento da expectativa de vida.

Essa estimativa crescente da população idosa é comprovada pelas projeções da Organização das Nações Unidas (ONU): “conforme as taxas de fertilidade decrescem, a proporção de pessoas com idade acima de 60 anos tende a triplicar em 2050, alcançando o número de dois bilhões de pessoas idosas" (GALLETI, 2014, p.8).

Tendo em vista essas considerações, compreendemos ser necessário (re)pensar em modos de incluir esses sujeitos nos processos educacionais, elaborando alternativas didáticas e pedagógicas que formem futuros professores para a educação dos adultos idosos, sobretudo aqueles afastados da escola por inúmeras contingências da vida.

Uma das formas utilizadas na disciplina ETI foi trabalhar com a perspectiva etnissociológica de Daniel Bertaux (2010), por acreditarmos que esse seria um modo de aproximar estudantes em formação inicial das reais necessidades dos sujeitos idosos e das especificidades por eles demandadas. A opção pela metodologia das narrativas de vida transversalizou as atividades na disciplina, embasando tanto o trabalho desenvolvido em sala de aula, quanto a análise apresentada neste relato. 


\section{Narrativas de vida como possibilidade didático-pedagógica na formação de professores}

Nos amparamos em Bosi para justificar a opção pelo trabalho com narrativas na formação disciplina ETI:

[...] a conversa evocativa de um velho é sempre uma experiência profunda: repassada a nostalgia, revolta, resignação pelo desfiguramento de paisagens caras, pela desaparição de entes amados, é semelhante a uma obra de arte. Para quem sabe ouvi-la é desalienadora, pois contrasta a riqueza e a potencialidade do homem criador de cultura com a mísera figura do consumidor atual (BOSI, 1994, p.41).

Uma narrativa pode ocorrer de forma natural: basta apenas uma questão e uma escuta sensível sobre as histórias que os idosos têm para contar. A metodologia empregada na disciplina ETI envolveu alguns passos em sua construção.

Primeiramente, discutimos a importância da história oral e das narrativas como instrumentos de reflexão e de estudos. Posteriormente, os estudantes, em grupos, selecionaram os entrevistados com idade acima de 60 anos.

A partir desse momento, foram observadas as orientações de Bertaux (2010) para elaboração das entrevistas. Conforme o autor, a entrevista é concebida como uma estratégia em que o pesquisador pede a uma pessoa - o informante - que lhe conte toda ou parte de uma experiência vivida. Conforme Bertaux (2010), a coleta das narrativas implica uma série de cuidados em sua realização, tais como:

- $\quad$ Abertura do trabalho de campo - Momento da construção da identidade do pesquisador e clarificação aos sujeitos da pesquisa das suas intencionalidades;

- $\quad$ Agenda do encontro - Envolve o modo de interpelação dos entrevistados para o agendamento, que deixe os sujeitos à vontade para escolherem dia, hora e locais mais apropriados para eles.

- $\quad$ Preparação da entrevista - É uma etapa crucial, pois é preciso ter um roteiro em mãos, bem como um caderno de campo no qual o pesquisador possa fazer as anotações. As perguntas precisam ser claras e pouco numerosas, possibilitando maior espontaneidade;

- $\quad$ Condução da entrevista - Considera dois momentos: no primeiro, se encoraja o 
entrevistado a contar a sua vida, estimulando-o e mostrando interesse no que é contado. No segundo, pode-se retornar ao roteiro, caso haja algum ponto que não foi abordado na fala dos sujeitos. Outros cuidados são necessários: aceite pelo entrevistado de que a conversa seja gravada; não interrupção da fala; solicitação de esclarecimentos, se necessário; administração do inesperado e das emoções dos sujeitos, procurando encerrar a entrevista com questões que tragam à lembrança momentos felizes.

Considerando esses cuidados teórico-metodológicos, escolhemos como filtro de construção das narrativas a trajetória de escolarização dos idosos.

De acordo com Bertaux (2010, p.51), "na narrativa de vida etnossociológica, forma oral e mais espontânea, e, sobretudo, forma dialógica, o sujeito é convidado pelo pesquisador a considerar suas experiências passadas através de um filtro". Esse é considerado um tema central do diálogo entre entrevistador e entrevistado e é estabelecido no primeiro contato entre ambos, como se fosse um contrato. Desse modo, ao escolhermos como filtro a trajetória da escolarização dos idosos, acreditamos ser possível melhor entender as razões que os levaram à permanência ou à evasão escolar.

Ao tomarmos como filtro das entrevistas o processo de escolarização dos entrevistados, não podemos desconsiderar outros domínios de vida, indissociáveis das dificuldades na trajetória escolar, seja de forma positiva e/ou negativa. De acordo com Bertaux (2010), a escola realiza uma espécie de modelagem para que os indivíduos aprendam os mesmos valores, a mesma língua e os mesmos códigos de conduta para bem viver em sociedade. No entanto, por outro lado, ela forma para a diversidade.

Cabe salientar que não consideramos os entrevistados como passivos no processo da entrevista ou como objetos de pesquisa sobre o filtro escolhido, mas sim como pessoas que têm histórias para contar e compartilhar. A entrevista tende a se transformar em uma conversa aberta, para que a pessoa relembre e conte sua história de forma nítida e se sinta à vontade para falar, contando, com riqueza de detalhes, as experiências vividas.

A partir desse trabalho de seleção do filtro, os estudantes formularam as questões para a entrevista. Foram entrevistados 08 (oito) idosos, sendo 02 (dois) homens e 06 (seis) mulheres com idade entre 60 a 78 anos.

Com as entrevistas em mãos, registradas por escrito ou em áudio, os estudantes 
construíram as narrativas. A orientação dada pela professora foi a de que eles escrevessem em primeira pessoa - se colocando no lugar do sujeito idoso - ou em terceira pessoa - contando a história para um público ouvinte determinado.

\section{Narrativa de vida: constructos utilizados e definição do corpus de análise}

Para subsidiar a análise das narrativas realizada neste trabalho, foram considerados os constructos de análise domínios da existência e linhas quebradas, propostos por Bertaux (2010).

Os domínios da existência fazem parte da história do ser humano, visto que este vive em grupo e não sozinho. Em nossa linha da vida ocorre uma série de interações com outras pessoas, em diversos espaços de construção da nossa subjetividade. Considerando esse pressuposto, o autor citado apresenta e discute quatro domínios de existência: as relações familiares $e$ interpessoais, a experiência da escola e da formação dos alunos, a inserção profissional e o emprego. Podemos observar que esses domínios se articulam e se atravessam durante toda a linha da vida de uma pessoa.

Nas trajetórias de vida, há domínios que exercem, em determinado tempo, maior influência sobre as escolhas de uma pessoa, podendo alterar projetos e sonhos individuais. Isso implica considerar uma trajetória existencial como uma Coluna Vertebral, definida por Bertaux (2010), como a linha de uma vida composta por percursos altos e baixos. A maior parte das linhas de vida não são lineares, elas são constituídas por linhas quebradas, no sentido geométrico do termo: elas são certamente contínuas, mas fazem ziguezagues: “Em sua maioria, as existências são ao contrário sacudidas por forças coletivas que reorientam seus percursos de maneira imprevista e geralmente incontrolável" (BERTAUX, 2010, p.48-49).

Ao considerarmos as condições de existência, há que se atentar para as diferenças de classe, de gênero e de raça, pois essas condicionam os modos de vida e escolhas dos sujeitos em suas interações com o mundo. Nesse sentido, Paulo Freire (1987) traz a denúncia da contradição existente entre opressores e oprimidos, principalmente em sua proposição de um método de alfabetização/conscientização de jovens e adultos.

A tomada de consciência que atravessa as histórias analisadas e os caminhos de 
superação são materializados nas narrativas de vida selecionadas. Podemos afirmar que a técnica das entrevistas de Bertaux (2010) constitui-se como uma possibilidade de que os sujeitos possam dizer a sua palavra, promovendo, ao mesmo tempo, uma reflexão sobre seu processo vivido. A entrevista assume, assim, o caráter dialógico, tão caro a Freire:

Quando tentamos um adentramento no diálogo, como fenômeno humano, se nos revela algo que já poderemos dizer ser ele mesmo: a palavra. Mas, ao encontrarmos a palavra, na análise do diálogo, como algo mais que um meio para que ele se faça, se nos impõe buscar, também, seus elementos constitutivos. Essa busca nos leva a surpreender, nela, duas dimensões; ação e reflexão, de tal forma solidárias, em uma interação tão radical que, sacrificada, ainda que em parte, uma delas, se ressente, imediatamente, a outra. Não há palavra verdadeira que não seja práxis. Daí, que dizer a palavra verdadeira seja transformar o mundo (FREIRE, 1987, p.44).

É através da análise das narrativas produzidas pelas estudantes que fizeram as entrevistas com os idosos, que acreditamos poder compreender as trajetórias e aprender com elas. Para tanto, selecionamos duas narrativas, dado o grande número de discussões que cada uma delas poderia produzir. Optamos, assim, por escolher duas histórias: a de uma mulher e a de um homem, por entendermos que essa diferença poderia incidir sobre as singularidades dessas mesmas trajetórias escolares.

Esses sujeitos serão identificados com os nomes fictícios Amélia e Amaro para preservação de suas identidades, bem como serão omitidas informações que possam, de algum modo, permitir qualquer identificação.

Outros critérios para a definição das narrativas a serem analisadas foram: a facilidade de acesso dos estudantes a esses sujeitos; e narrativas que possibilitassem uma análise mais qualitativa das categorias de Bertaux (2010). Além desses critérios, foi preciso considerar a concessão de autorização dos idosos entrevistados para divulgação das narrativas em forma de relatos de experiência. $\mathrm{Na}$ análise, os excertos das narrativas dos idosos são apresentados em itálico para diferenciá-los das citações diretas dos autores, conforme determina a NBR6023 (ASSOCIAÇÃO BRASILEIRA DE NORMAS TÉCNICAS, 2018) para o caso das transcrições de trechos oriundos das técnicas de entrevista. 


\section{Caminhos trilhados no processo de escolarização de Amélia e de Amaro}

Para Bosi (1994, p.21), "uma lembrança é um diamante bruto que precisa ser lapidado pelo espírito". Ao compreender essas memórias como objeto de estudo sobre as trajetórias escolares dos idosos na disciplina ETI, selecionamos excertos das narrativas produzidas pelos estudantes a partir das entrevistas realizadas que remetessem aos construtos teóricos de Bertaux (2010): domínio da existência e linhas quebradas. Cumpre lembrar que devemos levar em consideração que estes domínios da existência são subdivididos em: as relações familiares e interpessoais (RFI), a experiência da escola e da formação (EF) dos alunos, a inserção profissional (IP) e o emprego (E).

\section{Amélia: a luta contra os preconceitos de gênero}

As estudantes do grupo 01 apresentaram a narrativa na terceira pessoa do singular, utilizando como material o diálogo estabelecido na entrevista. Observamos, na linha de vida de Amélia, uma mulher de 65 anos, a luta contra os preconceitos em busca de um sonho. Esses percalços foram produzidos no âmbito das relações interpessoais e familiares, primeiro domínio da existência. Inicialmente, a entrevistada relata sobre seu contato com a educação formal, considerada um lugar de opressão e, sobretudo, de medo dos professores:

[...] Eu comecei a estudar com sete anos, na primeira série, ia pra escola normalmente, e era muito diferente da época atual. Quando íamos pra escola, a gente tinha um medo de professor, Nossa Senhora! Um horror de professor. Você acha que é igual hoje tia pra lá, tia pra cá?! Nossa mãe! Quando te apontava o dedo pra fazer uma leitura, cê ficava assim oh, tremendo [...] Não sei por que a gente era tão reprimido assim na escola e em casa.

Sua jornada escolar foi difícil, uma vez que em sua cidade não havia a 5ạ série (atual 6으 ano) e, a partir desta, o estudo era pago. Vejamos, na sequência, um excerto que demonstra a força do domínio RFI:

[...] Naquela época a gente fazia um período de admissão, pra você ir pro Ginásio, de quinta série a oitava série [...] A gente dependia do meu avô, e ele 
não queria que eu estudasse fora, por que nós já éramos oito irmãos, e ele falava que não tinha condição financeira pra estudar [...] E tinha que pagar a partir da quinta série.

Em 1965, porém, um acontecimento levou esta entrevistada a retornar aos estudos: a morte de seu avô. Após esse período, ela arrumou emprego de professora substituta. Esse evento pode ser considerado como uma linha quebrada, pois a leva a uma série de transformações que envolvem os três domínios da existência de modo articulado: EF, IP, E.

Em relação à sua inserção profissional (IP), Amélia narra seu trabalho como professora, dizendo que guardava boas e engraçadas lembranças, apesar de não ter se encontrado na profissão:

[...] No ano seguinte eu vim dar aula aqui (cita cidade), fazendo primeiro ano do segundo grau. Durante dois anos dei aula para turma de alfabetização, tinha que ensinar as crianças a ler e escrever. Foi muito, muito gratificante. Todas as turmas eram de 40 alunos, as salas lotadas. Eu só lembro que eu não tinha perfil para ser professora [...]. E nessa época não tinha merenda direito na escola, era muito diferente de hoje. Inclusive, o comportamento dos meninos era diferente, antigamente eles faziam muito mais bagunça. Nossa!

Em momento mais tardio de sua vida, Amélia disse ter encontrando uma profissão que Ihe atraiu: a enfermagem, pelo cuidado com o ser humano e, ao mesmo tempo, pensava em seus onze irmãos. Acreditava que assim poderia oferecer condições melhores para eles, lhes abrindo caminho para que seguissem seus destinos. Porém, mais uma vez, ela encontrou obstáculos por causa de opiniões contrárias de outros e de sua mãe. Essas pessoas não viam com bons olhos a profissão de enfermeira.

Como vimos, o domínio familiar e interpessoal exerce novamente influência em sua trajetória de vida. Contudo, diferentemente do que aconteceu no passado, Amélia resistiu aos ditames familiares, assumindo seu desejo de ser enfermeira.

[...] minha mãe trancava a cara, botava todos os empecilhos do mundo pra eu não sair de casa, pra não estudar fora. Ela falava: porque enfermeira é mal falada, que não é profissão de mulher direita. Eu ouvia cada uma, que só Deus sabe. Ainda bem que desde o início eu não fui de dar muito papo pra opinião alheia. Mas, quase ninguém me apoiava, sabe?! Papai, dona Zizi, dona Glória, eram os únicos que me apoiavam. 
É válido mencionar que estes ditames estão envoltos por uma esfera familiar tradicional em que as mulheres "estão destinadas exclusivamente à esfera dita doméstica e aos seus trabalhos antroponímicos como mãe, mas também nora, avó, filha mais velha ou criada" (BERTAUX, 2010, p.54). Entretanto, saindo desta vertente tradicionalista, no final de 1972 Amélia foi para outra cidade fazer um curso pré-vestibular e, em 1974, ingressou na graduação em enfermagem.

Em sua narrativa, todos os domínios da existência citados por Bertaux aparecem, porém, analisamos que os mais fortes foram as Relações Familiares e Interpessoais e o Emprego. Na análise do processo de produção das narrativas, as estudantes da disciplina ETI que fizeram a entrevista com Amélia escreveram que:

[...] foi uma experiência fantástica de conhecimento da vida de outra pessoa, de ouvir o seu relato único. Percebemos, em todos os fatos narrados, que estes formam as linhas quebradas e os domínios da existência de sua história. História esta que não passa imune à realidade social, econômica e política do momento vivido, visto que as dificuldades financeiras, a estrutura familiar com doze filhos, as limitações do sistema escolar, os preconceitos vividos pela mulher, tudo isso faz parte de um contexto mais amplo de sociedade e, talvez, de mundo na época (Estudantes ETI/ Entrevista Amélia).

Apesar de a escola realizar uma espécie de modelagem dos sujeitos, há espaços de resistência que produzem a diversidade. Conforme Bertaux, "ela visa, primeiramente, socializar e desenvolver as capacidades dos indivíduos: nisso, como bem observou Durkheim, ela produz, simultaneamente, o mesmo e o diferente" (BERTAUX, 2010, p.55).

A entrevistada se formou em enfermagem porque se sentia apta para isso, mesmo convivendo com impedimentos, dúvidas e inúmeras dificuldades. Essas experiências revelam linhas quebradas que se formaram nas relações familiares e interpessoais, mas que tiveram seus efeitos, igualmente, na experiência escolar, na inserção profissional e nas questões de emprego.

\section{Amaro: um elogio à escola}

O segundo grupo entrevistou um homem de 61 anos, que iniciou sua vida de estudos em 1961, com seis anos de idade, em uma instituição de ensino localizada em uma zona rural 
próxima da sua casa. Foi nesse contexto que Amaro estudou do 10 ao 5으 ano do Ensino Fundamental.

Durante a descrição de sua trajetória escolar, ele contou que viveu em ambiente marcado por regras rígidas, presenciando alguns castigos físicos, que não o afetavam diretamente, mas impactavam seus amigos quando desrespeitavam as regras impostas, tais como: palmatória, ajoelhar no milho, varadas, entre outros casos.

Amaro relatou também os percalços em relação à sua permanência em uma instituição de ensino, as motivações para sua persistência, reafirmando a existência do domínio da experiência da escola e da formação (EF):

A ida à escola era bem difícil, andava em torno de cinco quilômetros a pé para chegar, ia com pés descalços, em dias de chuva era ainda mais difícil muita lama, chegava todo molhado e sujo, mas mesmo assim me sentava e assistia à aula. Gostava muito da escola e da minha professora, ela foi um dos pontos mais marcantes do período que estudei, ela era uma ótima professora, muito rígida, mas nos ensinava com carinho tudo que ela sabia, não se importava com a sala de aula que era pequena e simples. Para ela, o que importava era a organização das carteiras e o quadro negro sempre limpo [...]. Outro momento marcante na escola em que estudei era o espaço em que ela estava, por ser de zona rural, tinham muitos bichos, árvores, rios e cachoeiras, o que nos possibilitava ter uma imaginação muito grande, pois através desses espaços a gente inventava tudo o que queríamos. Aprendíamos na escola a fazer brinquedos com matéria prima, vinda da natureza. Mesmo com toda dificuldade, tudo isso era mágico, não tinha materiais escolares bonitos, nem mochilas, carregava o pouco material que tinha em sacos de embalar alimentos ou em uma bolsa que minha mãe fazia, que chamava de embornal.

Seu relato demonstra como as condições materiais de vida condicionam nossa relação com o mundo, incluindo com a escola. As evocações trazidas no processo narrativo de Amaro evocam um passado que geralmente é visto com nostalgia, não só em relação à escola, mas ao ambiente natural e social nos quais as experiências se produziram.

Assim, é possível dizer que a compreensão das ações de um sujeito implica a análise das relações com os grupos que fazem parte de seu contexto social. Visto que, "[...] seu próprio projeto de vida, decidido em certo momento da existência, não foi elaborado in abstrato dentro de uma consciência isolada, mas foi falado, dialogado, construído, influenciado e negociado ao longo da vida em grupo (BERTAUX, 2010, p.53). 
Percebemos essa influência de um determinado grupo, normalmente, sujeitos mais velhos e ditos provedores do sustento da família, pois ela impede e/ou dificulta alguns sonhos. Amaro retrata, posteriormente e com certa tristeza, as dificuldades de apoio familiar, sobretudo, a ausência de apoio paterno e o modo rígido de sua educação familiar, que o levou a buscar, no seio da família mais ampla, o suporte necessário, mas que não o poupou dos limites impostos por sua materialidade de vida, que Ihe tornaram a inserção ao universo escolar igualmente difícil.

Infelizmente não tive oportunidade de prosseguir nos estudos, meu pai era muito rígido e ignorante, me colocou para trabalhar muito novo e não aceitava erros. Ele me batia muito, não aguentei as agressões e sai de casa aos 11 anos de idade. Fui morar com meu tio, irmão da minha mãe, lá trabalhava na roça para ajudar meu tio, ficava muito cansado e como a casa dele era muito longe da escola, com isso eu comecei a faltar muito às aulas até que acabei parando de estudar no 5o ano primário. Os fatos de trabalhar muito cedo e morar longe da escola me atrapalharam a prosseguir nos estudos.

Identificamos a presença dos domínios Emprego, Relações Familiares e Interpessoais e Inserção Profissional na vida de Amaro, que acarretaram a interrupção de sua trajetória escolar: "Na educação que tive na escola eu não mudaria nada, pois foi graças a essa educação mais rígida que hoje sou o que sou, talvez o que queria que fosse diferente no período em que estudei foram as dificuldades, e por ter que começar a trabalhar muito cedo e ter que parar de estudar".

Tais compreensões sobre os processos vivenciados, quando tomadas à distância, indicam a força material das condições de produção em que as experiências se produziram, possibilitando maior compreensão das histórias narradas pelos sujeitos. Conforme Bosi (1994, p.18), os velhos são fontes de cultura e, nesse sentido, o passado, como modo de conservação da cultura, "é o alargamento das fronteiras do presente, lembrança de promessas não cumpridas". Assim, os diferentes domínios da existência se entrecruzam, condicionam e alteram sonhos e desejos.

A ideia de que em alguns momentos a vida poderia ter sido diferente só é possível de ser produzida após os acontecimentos, gerando uma nova consciência sobre a historicidade, que acompanha a evocação dos sujeitos sobre seu passado. Relembrar torna-se, assim, um ato não só relativo à memória (tal como a vida aconteceu), mas um ato de reflexão sobre o acontecido e nossas escolhas e, por que não dizer, um ato de compreensão de si e do mundo circundante, conectando passado, presente e futuro. 
Qual seria, então, a função social dos velhos? E como as narrativas podem contribuir para que possamos compreender as trajetórias dos sujeitos, nesse caso, as escolares? Para Bosi (1994, p.18), a "função social do velho é lembrar e aconselhar". Porém, é preciso estar alerta para o artifício da sociedade capitalista, que ao destruir os suportes materiais de memória, bloqueia os caminhos da lembrança, silenciando os rastros do passado. Por isso, a importância de se recuperar essas memórias de escola e de vida, que materializam as condições sócio-históricas dessas existências: contexto econômico, político, social, cultural e ideológico.

Essas histórias poderiam ser diferentes? Alguns elementos das narrativas de Amaro e de Amélia indicam que as linhas quebradas são diferentes para homens e mulheres.

\section{Considerações e provocações}

Ao analisarmos os percursos de vida escolar de Amélia e Amaro, tivemos acesso às histórias dos sujeitos entrevistados. Os excertos apresentados e analisados permitem observar a relevância do resgate das memórias escolares, pois estas são dependentes dos imaginários sociais de cada época, do contexto social, cultural, econômico e educativo em que essas vidas vão se constituindo, produzindo diferentes modos de existência.

$\mathrm{Na}$ perspectiva etnossociológica de Bertaux (2010), as experiências vividas se transformam em ricos materiais históricos, possibilitando explorar conhecimentos sociográficos e sociológicos. Quando trazidas para a formação de professores, revelam-se como uma oportunidade de promoção do encontro intergeracional entre alunos do curso de Pedagogia e idosos, permitindo a criação de espaços de escuta entre as gerações e, concomitantemente, novas relações com o tema da velhice.

Questões relativas à educação na terceira idade e à formação para se trabalhar com esse público demonstram que muitos idosos buscam nos estudos uma forma de resgatar sonhos antigos, alterados pelas contingências da vida. Nesse sentido, concordamos com Búfalo (2013), ao afirmar que as instituições educativas podem se configurar como um novo espaço de educação dos sujeitos idosos, tanto na educação formal quanto não formal.

Uma importante consideração a ser feita é relativa às questões de gênero que se materializaram nas escolhas profissionais de Amaro e de Amélia. Nesse aspecto, podemos nos 
remeter, em sentido metafórico, à letra da música composta em 1942, por Mário Lago e Ataulfo Alves, que diz: "Amélia não tinha a menor vaidade, Amélia é que era mulher de verdade". Os sentidos produzidos por essa letra nos fazem problematizar o modo como os imaginários sobre papéis femininos e masculinos de cada época podem condicionar a vida dos sujeitos de acordo com seu gênero, produzindo oportunidades desiguais que podem redundar em trajetórias escolares discrepantes.

Podemos, assim, afirmar que os discursos de perpetuação das desigualdades entre homens e mulheres ao longo dos séculos produz diferenças nas oportunidades e escolhas profissionais. Este fator é perceptível na trajetória de vida de Amélia, que se tornou mal vista aos olhos dos familiares por querer realizar uma profissão entendida como indigna de uma mulher naquele contexto histórico-social. Essa situação nos permite perceber que a educação para mulheres se volta, em muitos casos, para profissões que as habilitem para um confinamento em um mundo interior. Em contrapartida, os homens são preparados para profissões de prestígio, tidas como pertencentes ao mundo exterior (BLAUDT; RANGEL, 2018).

A narrativa de Amélia, contrastada com a de Amaro, demonstra que as linhas quebradas são relativas às questões de gênero, revelando aspectos sociais e culturais que atravessam as vidas de homens e mulheres de modo diferente. Apesar de evocar memórias do passado, nos fazem observar como a sociedade contemporânea ainda carrega as marcas dos valores dos nossos antepassados, parecendo retornar e tomar vida no contexto atual, no qual a luta pela igualdade de gêneros ainda é árdua e permanente.

\section{Referências}

ALMEIDA, T.; LOURENÇO, M. L. Envelhecimento, amor e sexualidade: utopia ou realidade? Revista Brasileira de Geriatria e Gerontologia, Rio de Janeiro, v.10, n.1, p.101-113, 2007. Disponível em: https://www.redalyc.org/pdf/4038/403838772008.pdf. Acesso em: 29 maio 2020.

ASSOCIAÇÃO Brasileira de Normas Técnicas - ABNT. NBR 6023: informação e documentação: transcrição de entrevistas. Rio de Janeiro, 2018. Disponível em: https://normasabnt.espm.br/index.php?title=Transcri\%C3\%A7\%C3\%A3o_de_entrevistas. Acesso em: 25 maio 2020. 
BERTAUX, D. Narrativas de vida: a pesquisa e seus métodos. São Paulo: Paulus, 2010.

BLAUDT, V. L.; RANGEL, M. Discriminação de gênero na educação: a história edificando as desigualdades. Caderno Espaço Feminino, Uberlândia, v.31, n.1, p.182-2000, 2018. Disponível em: http://www.seer.ufu.br/index.php/neguem/article/view/41237/pdf. Acesso em: 29 maio 2020.

BOSI, E. Memória e sociedade: lembrança de velhos. São Paulo: Editora da Universidade de São Paulo, 1994.

BRASIL. Política Nacional do Idoso. Estatuto do idoso: lei federal no 10.741, de 01 de outubro de 2003. 2.ed. Brasília, DF: Ministério da Saúde, 2006. Disponível em:

https://bvsms.saude.gov.br/bvs/publicacoes/estatuto_idoso_3edicao.pdf. Acesso em: 29 maio 2020.

BÚFALO, K. S. Aprender na terceira idade: educação permanente e velhice bem-sucedida como promoção da saúde mental do idoso. Revista Kairós: Gerontologia, v.16, n.2, p.195-212, jun. 2013. ISSN 2176-901X. Disponível em: https://revistas.pucsp.br/kairos/article/view/18533. Acesso em: 30 ago. 2019.

FREIRE, P. O homem e sua experiência/alfabetização e conscientização. In: FREIRE, P. Conscientização: teoria e prática da libertação: uma introdução ao pensamento de Paulo Freire. São Paulo: Cortez \& Moraes, 1980. p.13-50.

FREIRE, P. Pedagogia do oprimido. 17.ed. Rio de Janeiro: Paz e Terra, 1987.

GALLETI, T. A. I. A proteção social ao idoso dependente na seguridade social brasileira. 2014. 132f. Dissertação (Mestrado em Direito Político e Econômico) - Universidade Mackenzie, São Paulo, 2014. Disponível em: http://tede.mackenzie.br/jspui/handle/tede/1134. Acesso em: 30 ago. 2019.

JOVCHELOVITCH, S.; BAUER, M. W. Entrevista narrativa. In: BAUER, M. W.; GASKELL, G. (org.). Pesquisa qualitativa com texto, imagem e som: um manual prático. Petrópolis: Vozes, 2002. p.90-113. Disponível em: http://revista.facfama.edu.br/index.php/PedF/article/view/260/211 Acesso em: 29 maio 2020.

LAGO, M. Ai que saudades da Amélia, 1942. Disponível em: https://www.vagalume.com.br/mario-lago/ai-que-saudades-da-amelia.html. Acesso em: 07 jan.2020.

NERI, A. L.; YASSUDA, M. S. (orgs.). Velhice bem-sucedida: aspectos afetivos e cognitivos. Campinas: Papirus, 2004.

NERI, A. L. Qualidade de vida e idade madura. São Paulo: Papirus, 1993. 
STUCCHI, D. Os programas de preparação a aposentadoria e o remapeamento do curso da vida do trabalhador. 1994. 232f. Dissertação (Mestrado em Antropologia Social) - Universidade Estadual de Campinas, Instituto de Filosofia e Ciências Humanas, Campinas, 1994. Disponível em: http://www.repositorio.unicamp.br/handle/REPOSIP/28059. Acesso em: 19 jul. 2018.

ZIMERMAN, G. I. Velhice: aspectos biopsicossociais. Porto Alegre: Artes Médicas Sul, 2000.

Recebido em fevereiro 2020.

Aprovado em julho 2020. 